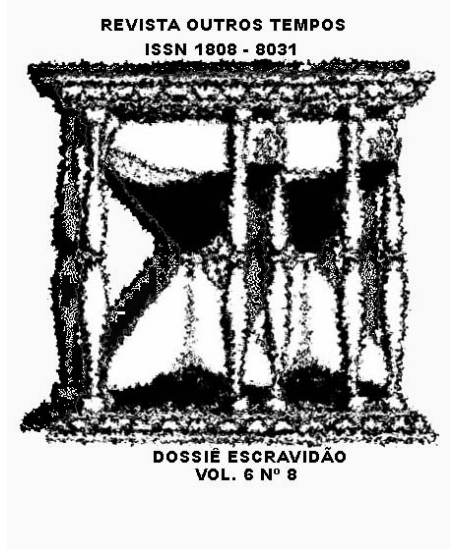

\title{
USOS E ABUSOS DO ENCONTRO FESTIVO: Identidades, Diferenças e Desigualdades no Maranhão dos Bumbas (c. 1900-50)
}

\author{
Antonio Evaldo Almeida Barros \\ Doutorando em História / UNICAMP \\ eusouevaldo@yahoo.com.br
}

\section{RESUMO}

É freqüente e difundida a idéia de que a festa, particularmente a festa à brasileira, seria capaz de mediar, apaziguar ou mesmo eliminar múltiplas e variadas diferenças entre os sujeitos. No caso do Brasil, a lapidação dessa imagem da festa se efetivaria sobretudo no contexto da ideologização da mestiçagem brasileira particularmente a partir dos anos 1920-30. Neste período, diferentes intérpretes da nação e das regiões brasileiras buscavam identificar seus símbolos coletivamente partilhados, e a festa se tornaria a ocasião máxima para se observar essa partilha amistosa e harmônica. Entretanto, um conjunto significativo de pesquisadores têm se esforçado em seguir um outro caminho, evidenciando que a festa é uma ocasião privilegiada para se observar as tensões, conflitos, diferenças e desigualdades. Aqui, festas como o carnaval e os festejos juninos - cujos principais elementos no Maranhão, os bumbas-meu-boi, são inscritos como modeladores e mediadores de ser maranhense poderiam ser interpretadas como um lugar particular para se notar o funcionamento das diferenças e desigualdades. Para além da mistura e do encontro, pode-se perceber que nessas festas, longe de se suspender conflitos e se revitalizar comunidades imaginadas nacionais e regionais, as hierarquias sociais são ritualizadas e teatralizadas.

Palavras-chave: Festas. Diferenças. Desigualdades. Identidades. Bumba-meu-boi.

\begin{abstract}
There is a common notion that festivals, and particularly Brazilian ones, are capable of mediating, deemphasizing, or even eliminating differences among subjects. In Brazil, this image of the festival was cultivated as part of Brazilian mestiçagem ideology, especially from 1920-30 on. During this period, many interpreters of the nation and its regions sought to identify its shared symbols. They often portrayed festivals as ideal occasions for observing the harmonious, collective sharing of symbols. However, another group of researchers has described the festival as a moment in which tensions, conflicts, differences and inequalities come to the fore. In this paper, festivals such as Carnival and St. John's - that in Maranhão has as principals elements the bumbas-meu-boi, that are inscribed as key mediating and modeling of "being Maranhense" - are interpreted as key sites at which to observe differences and inequalities. Despite the mixture and coming together of groups, we argue that these festivals served to ritualize and dramatize social hierarchies, rather than to suspend conflicts and revitalize imagined regional and national communities.
\end{abstract}

Keywords: Festivities. Differences. Inequalities. Identities. Bumba-meu-boi.

\footnotetext{
- Uma versão preliminar deste trabalho foi apresentada no International Doctoral Summer School "Cultures of Inequality”, realizado de 01 a 03 de março de 2009 em Joanesburgo, África do Sul, e no Fórum de Pesquisa "Culturas das Desigualdades", organizado pela Comissão de Relações Étnicas e Raciais (CRER) da 26a. Reunião Brasileira de Antropologia, realizada entre os dias 01 e 04 de junho de 2008, Porto Seguro, Bahia, Brasil.
} 
É difundido e duradouro o pressuposto de que "a Festa, no Brasil, constitui uma linguagem simbólica para a qual são traduzidos valores nacionais. Ela é capaz de mediar diferenças sociais e culturais, estabelecendo pontes entre grupos e suas realidades e utopias" (AMARAL, 1998). Esta seria a especificidade da "festa à brasileira" ou das ocasiões nas quais sujeitos de diferentes qualidades se inter-relacionam, a exemplo do "encontro", que teria sido fundamental para a construção do samba e da identidade nacional, realizado em 1926 no Rio de Janeiro entre Sérgio Buarque de Holanda, Gilberto Freyre, Pedro Dantas, Heitor Villa Lobos, Luciano Garret e Patrício, Donga e Pixinguinha (VIANNA, 1995). Esse "encontro", que ocorrera antes da publicação de Casa-Grande e Senzala (1933) e Raízes do Brasil (1936), "livros que foram fundamentais para a definição da identidade moderna brasileira", seria "um achado" para se compreender a história de "um país misturado, mestiço e onde o mito de igualdade entre as 'raças' estava no cerne da utopia", "um país que não teme esta mistura e faz dela a delícia e a dor de ser o que somos" (MAGGIE, 2005). E nada seria mais claro e inequívoco do que a festa para se demonstrar a particular capacidade da sociedade brasileira em lidar com as diferenças e desigualdades. Através das festas, entendidas como momentos ritualizados em que a nação se auto-representa, emergiria uma cultura nacional resultante de uma mistura de múltiplas tradições (DAMATTA, 1998).

De fato, uma “(con)fusão entre festas e identidade nacional [...] ganhou corpo nas ciências sociais e na historiografia nativa sobre o carnaval ou o samba". Assim, além de serem dotadas de transcendência, o que naturaliza e torna os momentos festivos equivalentes entre si, as festas seriam "dotadas de imanência, no sentido de constituírem ocasiões capazes de expressar identidades englobantes como, por exemplo, nacionalidade, ethos" (CUNHA, 2002, p. 14) e, acrescentaria, regionalidade. A lapidação dessa imagem da festa parece ter se tornado possível sobretudo a partir dos últimos anos da Primeira República e dos tempos de Vargas, quando se positivaria a mestiçagem no Brasil. Essa representação da festa não mais conseguirá se desvencilhar das discussões sobre diferenças e desigualdades sociais, especialmente aquelas racialmente determinadas, pois foi construída em diálogo ou confronto com questões suscitadas por essas diferenças e desigualdades.

Embora se possa reconhecer que o Brasil harmônico-festivamente pensado foi construído sobretudo desde o Rio de Janeiro, deve-se salientar também que esse fenômeno teve múltiplas faces em variadas nações e também regiões do país, a exemplo do Maranhão. Com efeito, ao mesmo tempo em que o Carnaval e seus sambas eram eleitos ocasiões e elementos nos quais se manifestaria exemplarmente a brasilidade, o São João e seus bumbas se tornavam momentos privilegiados para se observar plenamente a identidade, cultura, 
tradição e comunidade maranhense - lugar este que é anunciado, sobretudo a partir dos anos 1920, como festivamente compartilhado por todos, brancos, mestiços e negros, pobres, classes médias e ricos, homens e mulheres. ${ }^{1}$ De fato, estas duas ocasiões, a do Carnaval brasileiro e a do São João maranhense, têm sido tomadas por diferentes pesquisadores, especialmente antropólogos e historiadores, particularmente os que se apresentam ou são vistos como os intérpretes da nação brasileira e da região maranhense, para demonstrar que a festa é, antes de tudo, ocasião para se observar misturas, encontros e mediações culturais, que, enfim, a região e a nação se alimentam e se revelam na festa.

Além de não se direcionar à compreensão de como as desigualdades e tensões sociais produzem ou se manifestam nas práticas culturais, nessas abordagens têm-se interpretado a cultura, especialmente as ocasiões festivas, como variável que revelaria a sociedade "resolvendo" (sobretudo pacífica e harmonicamente) suas desigualdades. Entretanto, um conjunto significativo de pesquisadores, notadamente historiadores, têm se esforçado em seguir um outro caminho, evidenciando a festa como uma ocasião privilegiada para se observar as tensões, conflitos, diferenças e desigualdades (ver, por exemplo, CUNHA, 2001; 2002). Assim, sugeriria interpretar as festas como momentos significativos para se notar formas pelas quais os diferentes sujeitos e setores sociais olham uns para os outros, comentam, justificam, aceitam ou reproduzem as múltiplas diferenças e desigualdades.

É mais ou menos consensual o pressuposto de que as festas são capazes de traduzir experiências, expectativas e imagens sociais daqueles que as realizam, apresentando-se como objeto privilegiado para se estudar os movimentos de uma determinada coletividade, população, região, nação (ABREU, 1999; AMARAL, 1998; BAKHTIN, 1987; CUNHA, 2001, 2002; DAVIS, 1990; DAMATTA, 1998; DUVIGNAUD, 1983; SOIHET, 1998). Entretanto, a forma como esta "tradução" é elaborada revela profundas diferenças teóricas entre os pesquisadores e, obviamente, múltiplas posições ideológicas e políticas. Estes processos poderiam ser analisados tomando-se como lugar de análise o Brasil na primeira metade do século XX, exatamente o momento em que se afirmaria a brasilidade mestiça e harmônico-festiva, destacando-se aqui o Carnaval na tessitura da brasilidade (CUNHA, 2001), e o São João e seus grupos de bois na organização de identidade maranhense.

\footnotetext{
${ }^{1}$ Em documentos da primeira metade do século XX, a expressão mais utilizada para demarcar o que se poderia denominar de identidade maranhense (e que neste início de século XXI tem-se nomeado "maranhensidade") era "tradições maranhenses". Entretanto, tão ou mais importantes que essas nomeações diretas, em geral reveladoras sobretudo da visão das elites letradas, são os múltiplos meios através dos quais a região era negociada, o que conduz a um leque mais amplo de práticas e representações sociais.
} 
A literatura que trata do bumba-meu-boi no Maranhão, em sua maioria antropológica, costuma analisá-lo na contemporaneidade, destacando seus aspectos rituais (ver, dentre tantos outros, CANJÃO, 2001; CARVALHO, 1995; REIS, 2000). Nestes estudos, algumas vezes são elaboradas sínteses históricas lacunares, apresentando-se os bumbas em sua fase de rejeição pelos setores dominantes ou já no momento em que esses repertórios culturais estariam completamente consolidados enquanto elementos essenciais da identidade da região. Sob certo aspecto, escapam a esta perspectiva, Corrêa (2002), que, entretanto, detêm-se no papel dos intelectuais, os "mediadores", e Albernaz (2004), que centra sua análise a partir dos anos 1970, e considera a ação do Estado e, em especial, do "governo Sarney" como um elemento fundamental desse processo.

Diante disso, buscando explorar uma possibilidade analítica em grande medida deixada de lado pelas abordagens anteriores, argumento que, organizações festivas, a exemplo dos grupos de bumba-meu-boi que circulavam pela Ilha de São Luís do Maranhão durante os festejos juninos na primeira metade do século XX, podem ser interpretadas como elementos e ocasiões particulares para se pensar a dinâmica e processos de mudança social. ${ }^{2}$ A partir da análise dessas atividades seria possível reconstituir experiências de diferentes sujeitos e setores sociais, e entender aspectos de processos significativos das histórias maranhense e brasileira, notando-se, por exemplo, formas de exercício do poder numa sociedade hierarquizada e modos como os sujeitos lidavam com diferenças e desigualdades naquelas primeiras décadas do Brasil republicano. Assim, poder-se-iam entender formas como indivíduos e grupos diferentes entre si se apropriavam de um repertório comum, a exemplo dos bumbas, o que poderia desembocar em encontros amigáveis, mas também em situações de intensa violência, e quiçá observar a manifestação de formas e processos originais de reivindicação e construção do exercício da cidadania. Por fim, trata-se de tentar notar como diferentes narrativas acerca dos bumbas e do festivo São João maranhense poderiam servir para analisar um campo denso e tenso em torno do qual gravitavam questões sobre "raça", classe e identidade no Brasil dos anos 1900-40, quando os ambíguos campos das identidades da região e da nação freqüentemente se interconectavam.

\section{Diferenças, tensões e desigualdades num tempo festivo}

Quando chegavam os dias dos santos que gostam de fogo, a ilha de São Luís se convertia num "verdadeiro mundo carnavalesco" (O GLOBO - OGB, 2/7/1942), uma ocasião

\footnotetext{
${ }^{2}$ Sobre a cultura se relacionando à dinâmica social, ver, particularmente, DAVIS (1990) e THOMPSON (1998).
} 
ímpar de lazer e devoção, e sobretudo de muitas festas, tempo em que gente de todas as qualidades se espalhava pelas ruas, caminhos e estradas em busca de celebrações religiosas, bailes e jogos, danças, brincadeiras e tambores. Mas os sujeitos se apropriavam de maneira variada desse repertório festivo.

Diversas barracas, com suas bebidas, jogos e fuzarcas, eram montadas no Caminho Grande, uma longa e estreita estrada de terra que cortava horizontalmente a ilha, tendo ao lado, em parte de sua extensão, uma ferrovia ou linha de bonde, ligando a zona urbana da cidade, a oeste da ilha, à vila de Ribamar, no extremo leste de São Luís. As pessoas se deslocavam intensamente em busca dos pontos mais atrativos dos festejos em algum subúrbio ou vila. Muitos, sobretudo aqueles que viviam mais próximos daquela estrada, usavam caminhões, ônibus, locomotivas, bondes e carros. Outros, especialmente aqueles que habitavam as áreas mais rurais, viajavam em carros de boi e carroças. Mas ir a pé também era a opção de diversas pessoas. Assim, enquanto uma dezena de homens, entre "malabarismos e mandonismos" (BUZAR, 1998), tentava governar o Estado naquelas primeiras décadas de República e durante os tempos de Vargas, outros governos e desgovernos, freqüentemente em (des)encontro com aquela política "séria", seriam orquestrados nos festejos juninos.

Para os mais católicos, "todos os esforçoo" seriam para que São João, São Pedro e São Marçal “não se aborreçam com as homenagens prestadas” (DIÁRIO DO NORTE - DNT, 22/6/1940, p. 2); pulando fogueiras, que como pontos luminosos infindáveis clareavam a ilha durante aquelas noites, alguns confirmavam batismos ou escolhiam novos padrinhos e madrinhas, e até realizariam casamentos considerados lícitos sem a presença de clérigos (REIS, 1951, p. 66). Da perspectiva de diferentes cronistas, articulistas e outros letrados, este seria, antes de tudo, um "tempo de tradições", dos "costumes antigos", do "mundo pitoresco" (SACRAMENTO, 1868; VIANA, 1910; MACEDO, 1926; PEREIRA, 1929; COSTA, 1934; OLIVEIRA, A., 1939; OLIVEIRA, F., 1939; DONCRI, 1939; LEMOS, 1940; PINTO, 1941; PEDRO, 1941; MELO, 1952; COSTA, 1953; VIEIRA FILHO, 1954; ALVES, 1955). Já ao "pessoal do "pega e rasga"” (TRIBUNA - TRB, 22/6/1934), que gostava de dançar, interessavam mesmo eram os barracões de arrasta-pés espalhados pelos subúrbios, onde dominavam as músicas da época, a exemplo dos anos 1920-30, quando se "arrochava no maxixe e no carimbó" (TRB, 24/6/1930, p. 7).

Diferentes famílias, particularmente da gente de "bom tom" que residia no Centro de São Luís, costumavam organizar fartas ceias com pratos da culinária local em seus sítios onde veraneavam no Natal, Ano Novo e festejos juninos (PEREIRA, 1929; PEDRO, 1941; REIS, 1952). A molecada, por sua vez, empenhava-se sobretudo na queima de pequenos fogos, 
atirando-os aos pés dos seus iguais e dos adultos, algo que poderia ser visto como "perversidade" e "caso de polícia" (PACOTILHA O GLOBO - PGB, 26/6/1951, p. 4). Para os "amigos da pinga" (TRB, 25/6/1933, p. 2), esta era ocasião e motivo para beber e outras coisas mais. Moças e rapazes da "sociedade elegante" também não perdiam essa oportunidade, uma vez que podiam sair com seus blocos ou se divertir nos "bailes aristocráticos" (PACOTILHA - PCT, 21/6/1919, p. 1; DNT, 27/6/1939, p. 8; 21/5/1942; 25/6/1944, p. 6), cujos partícipes se pensavam como "o que existe de melhor em nossa sociedade" (DNT, 27/6/1939, p. 8). Os jovens das zonas mais rurais gostavam mesmo era dos "forrobodós" espalhados nos barracões e terreiros do interior da ilha, quando as "morenas" podiam deixar "os cabras moles de cansaço, sujos de poeira, derreados de somno" (PINTO, 1941, p. 11).

Os instrumentistas e cantores profissionais aproveitavam para preparar suas brincadeiras "de pura harmonia e sem batuque" (TRB, 22/6/1933, p. 6), desfilando com elas pelo perímetro urbano da cidade. Majores, delegados, chefes de polícia e policiais, de um lado, teriam a responsabilidade de fiscalizar o bom cumprimento das portarias que, de maneira geral, proibiam o uso de determinadas bebidas, demarcavam as vias públicas que deveriam ser usadas pelos brincantes e, sobretudo, estipulavam os lugares que diferentes organizações festivas poderiam percorrer; e, de outro, constantemente caíam eles próprios na fuzarca.

Este tempo de festas era também ocasião para a eclosão dos jogos discursivos acusatórios entre setores da política partidária, quando membros das diferentes oposições lembravam das péssimas condições das estradas e avenidas, e da situação sanitária de São Luís, o que, segundo eles, atrapalharia o desenrolar de um tempo festivo ainda mais intenso. Alguns funcionários públicos deviam aguardar ansiosamente a última semana de junho com seus dias de trabalho facultativo. Para o Batalhão do Exército, este era, a exemplo do carnaval e das festas cívicas, um tempo de preparar sua garbosa banda de música que desfilava e se apresentava nos principais pontos tomados pela folia. Já os comerciantes, particularmente donos de lojas de tecidos e de bares, que enchiam os jornais com propagandas de seus produtos, deviam aguardar com disposição esses festejos, ocasião ímpar de aquecimento de suas vendas. Os organizadores de barracas, terreiros e arraiais contratavam danças, cordões e brincadeiras para atrair para seus bairros e vilas a multidão que se deslocava durante as festas em busca de diversão. Até poetas, em composições existencialistas, inspiravam-se nos tempos das festas de junho, a exemplo de Jorge de Meirelles (1950) que, para refletir sobre a "estrada 
longa, no caminho incerto que nós trilhamos ao desconhecido", decanta "o bojo negro do céu / todo coberto de estrelas" que "parece o corpo de um bumba / no São João do universo".

De fato, no mês em que "tudo é festa" (JORNAL DO DIA, 24/6/1954, p. 4) no Maranhão, nada despertaria mais atenção da maioria dos diferentes e desiguais sujeitos que viviam em São Luís na primeira metade do século XX do que os grupos de bumba-meu-boi, que surgiam de todos os recantos e transformavam a ilha nessa temporada. Essas brincadeiras em geral resultavam de um pagamento de promessa feita a alguma entidade espiritual, sobretudo os santos do catolicismo, como São João, embora também haja notícias de que alguns voduns do tambor de mina gostavam de ter bois em seus terreiros por ocasião desses festejos. Às vezes, aquele que fazia a promessa era o mesmo que organizava o bumba. Essa promessa podia passar de geração a geração. Assim, preparando-se para as festas, bem antes do mês de junho, os grupos se formavam, organizavam-se e ensaiavam suas danças e toadas. Caprichava-se na montagem do "couro", uma cobertura de papel, tecido, veludo ou outro material de uma armação de madeira com o formato de um boi. Um mesmo agrupamento, composto por homens, mulheres e/ou crianças, e ainda seus acompanhantes, podia ter um ou mais couros, cuidadosamente nomeados, e também mais de um "miolo". Este era o homem que pegava o couro, colocava-o sobre o corpo e balançava-o, dando-lhe ritmo. Enquanto isso, os brincantes, em diferentes funções, tocavam matracas, pandeiros ou tambores, e repetiam em uníssono as toadas e canções do amo, o cantador e guia do bumba. Os grupos disputariam ferrenhamente alguns miolos, tocadores e, sobretudo, os amos, embora estes pudessem ser fiéis às suas "tropas". De fato, sabe-se que muitos deles eram os donos dos bois nos quais cantavam, dançavam ou tocavam. Alguns grupos eram contratados para fazer suas apresentações, outros, entretanto, pareciam fazê-lo gratuitamente, mas quase sempre ao menos em troca de tiquira (cachaça destilada de mandioca). Terminadas as festas, matava-se ritualmente o boi, uma ocasião de muitas dramatizações e encenações cômicas realizada geralmente no mês de julho, até que no outro ano ele seria ressuscitado e uma outra festa começava.

Era comum que sujeitos de diferentes setores sociais desejassem pagar uma promessa oferecendo um boi aos santos, para o que, pediam e patrocinavam outrem, em geral, um "dono" ou "dona" de boi, para que este organizasse a brincadeira. Situações como esta implicavam em muitos desdobramentos e constituíam ocasiões significativas para se observar formas de teatralização do poder, para se notar modos como os sujeitos acionavam determinadas estratégias e negociavam entre si em uma sociedade hierarquizada. 
Algumas vezes, os bumbas percorriam o centro de São Luís, embora isto fosse amiúde proibido. ${ }^{3}$ Além do fato de que alguns grupos ignoravam as proibições oficiais, o que poderia acarretar-lhes, por exemplo, a perda de suas licenças (DNT, 1/7/1939, p. 6), pessoas que ali moravam, muitas das quais promesseiras, podiam pedir para que algum boi se apresentasse à porta de suas casas (OGB, 17/6/1947). Padres e chefes de polícia - em certas situações, provavelmente porque não tinham outra escolha - podiam aceitar algumas argumentações dos brincantes, como a idéia de que o santo ficaria insatisfeito e a promessa seria descumprida se os bois deixassem de ir, por exemplo, até a Igreja de São João, localizada no centro da cidade, como ocorrera em 1952 (PGB, 28/6/1952). Estas situações parecem ter sido comuns e devem ter contribuído para que, em algumas ocasiões, como em 1949, fosse oficialmente liberada a ida dos bois ao centro durante os festejos (PGB, 31/6/1949), quando poucos dias antes uma tal situação era claramente proibida (MARANHÃO, 8/6/1949).

A caminho de seus locais de apresentação, como terreiros e arraiais, e à porta de bares, igrejas e casas, grupos de bois dos mais variados matizes e origens podiam se encontrar, bois "do mato" (TPV, 22/6/1934) e de "gente da cidade" (DNT, 26/6/1938, p. 1), organizados por sujeitos que se identificavam, de diferentes modos e intensidades, por amizade, status e profissão, família, sexo e geração, municípios, bairros e vilas, como o Campeão da Ilha do lavrador José de Souza que, com seu "batalhão", prometia representar bem seu lugarejo do interior de São Luís; o Prometido, uma justa oferenda a São José por ter facilitado os negócios de Almir Reis que, com um grupo de amigos, formou uma boa tropa, iniciando suas atividades na vila de Ribamar, onde era padroeiro aquele santo; (TPV, 22/6/1934) o Boi Afrontador, também resultado de uma promessa, mas esta feita a São João por um entregador de jornais (TRB, 24/6/1934, p. 5; 29/6/1934, p. 3); o Flor do Caju, organizado por um grupo de pescadores, marisqueiros e outros "marítimos"; o Boi do Belira, de responsabilidade de Antonio Nunes, motorista e inspetor de quarteirão de um subúrbio colado ao centro da capital, onde realizava seus ensaios (TPV, 22/6/1934); o boi de "dona" Teodora Costa, que estreou em 1932 como pagamento de promessa a São José (TRB, 24/6/1932, p. 7); o Boi de Guimarães, afamado e respeitado batalhão do interior do Maranhão, que vinha do continente à ilha enfrentando horas de viagem a barco, em uma área reconhecida como de difícil navegação, só para os festejos (PCT, 25/6/1924, p. 5; TBP, 29/6/1934, p. 3); o Boi da Maioba,

\footnotetext{
${ }^{3}$ Algumas vezes as portarias policiais proibiam a realização dos bumbas (PGB, 24/6/1905; OGB, 24/6/1948), mas geralmente o que se estabelecia eram critérios para a realização dos festejos juninos, determinando em especial exatamente até que ruas os bumbas poderiam brincar, tentando afastá-los do centro da cidade (PGB, 20/6/1918, p. 1; TRB, 23/6/1933; DNT, 24/6/1939, p. 3; OGB, 22/6/1940, p. 2; 24/6/1944, p. 2; MARANHÃO, $1946,1947,1948,1949,1952)$.
} 
da zona rural, afamado e temido pelo menos desde 1899 (PCT, 22/6/1899, p. 2), e que existe até os dias atuais, sendo nomeado nos anos 1930-40 como Imperador da Ilha; e o Reparador, do subúrbio da Madre Deus, que, em 1939, junto com o Imperador tiveram suas licenças cassadas por terem desobedecido a portaria que proibia que dançassem no perímetro urbano de São Luís (DNT, 1/7/1939, p. 6).

Ainda, os bois Prenda de Amor e El Dourado compostos por mulheres, no caso, "filhas de Eva" (TRB, 20/6/1930, p. 5; 26/6/1930, p. 2), e não de Maria! Bois de crianças (TRB, 24/6/1932, p. 7; JPQ, 22/6/1957, p. 5); o Flor do Comércio, boi provavelmente patrocinado por comerciantes, para cuja festa de morte todos eram convidados (PCT, 20/7/1928, p. 4); o Flor da Zona (DNT, 7/6/1938, p. 4), possivelmente uma referência às zonas de meretrício, muito comuns ao redor dos diferentes arraiais por onde se apresentavam os bumbas e se concentravam os festejos; o boi do "mulato" Secundino, amo cuja "voz agrada bastante, e tem boas inspirações", sobretudo defronte da "tropa adversária" (TRB, 25/6/1933); outro boi da Madre Deus, cujo amo de 1908 a 1939 foi Zé Igarapé, tido como "bom na trova e na capoeira" (OGB, 25/6/1947), e que chegou a ser vigiado pela polícia acusado de ter matado um membro do boi de Cururupu, município do interior do estado, em um confronto (PASSOS, 1997, p. 79-83).

Nesse cenário, era fácil que os grupos de bois se encontrassem, e nestas ocasiões era relativamente comum que eles explicitassem, usando palavras ou armas, suas diferenças, o que podia resultar em manifestações de violência generalizada, com "mulheres horrivelmente queimadas, homens feridos e creanças contundidas" (PCT, 25/6/1902, p. 1), "pauladas e facadas" (DNT, 27/6/1937, p. 4), "caçambadas e derramamento de sangue” (DNT, 30/6/1940, p. 5). Mas apesar de a imprensa argumentar que a prova da incivilidade, da irracionalidade e da perversão das classes pobres poderia ser verificada durante os festejos juninos, especialmente por ocasião dos encontros de bumbas, tudo indica que havia códigos e regras que guiavam os grupos de bois, norteando, inclusive (ou talvez sobretudo), seus confrontos, pois, como sugestivamente cantava um amo no início dos anos 1930, "vamos brincar com jeito, camaradas, pois a morte não é vingança e a pose não vale nada" (TRB, 25/6/1933). A violência certamente não era gratuita, como diziam os jornais. Obviamente, deve-se reconhecer que havia casos em que alguns grupos, ao encontrar-se, confraternizavam-se festivamente, e até poderiam produzir ritmos híbridos nessa oportunidade.

O fato é que a circulação dos bois pela ilha de São Luís durante os festejos juninos constituía um fenômeno generalizado. Parece ser evidente que eles, em sua maioria produzidos por gente das zonas rurais e dos subúrbios, eram capazes "de despertar o interesse 
mesmo dos nascidos e criados na cidade" (MACEDO, 1926), de "brancos e pretos, velhos e moços" (OGB, 2/7/1942, p. 4). De certo modo, seus sentidos mais explícitos eram universais a todos. Antes de tudo, porém, esta é uma ocasião para se notar que são diversas as formas como indivíduos e grupos diferentes entre si se apropriam de um repertório comum, a exemplo dos bumbas. Nesta perspectiva, permitindo múltiplas leituras, o boi constitui um símbolo cuja análise pode revelar, de acordo com as circunstâncias, múltiplas formas de contato e interação sociais, ritualização de conflitos, negociações amigáveis, mas também situações de aguda violência; enfim, ocasião para se perceber como diferenças e desigualdades funcionam efetivamente no cotidiano dos sujeitos, e como estes se submetem ou manipulam essas heterogeneidades e dessemelhanças.

Os grupos de bumba-boi eram guiados por regras, acordadas oralmente ou mesmo por escrito. De fato, eles costumavam ser bastante organizados, com ensaios, apresentações, contratos e viagens pré-definidas. Os donos dos bois deviam fechar acordos com promesseiros, e com aqueles mais especializados, como amos, tocadores e miolos. Era grande a preocupação com a indumentária dos brincantes, a ornamentação dos materiais, a produção musical, poética e dramática dos bumbas. Os registros de toadas (por exemplo, TBP, 25/6/1933; DNT, 2/11/1939; OGB, 25/6/1947; 5/7/1948) e das múltiplas dramatizações que costumavam ser realizadas durante as apresentações possibilitam observar agendas sociais significativas para os brincantes, e que se tornavam públicas. Os temas freqüentes dessas canções e dramatizações faziam referência sobretudo a elementos do cotidiano desses sujeitos, das suas histórias pessoais, do povoado, da região, da nação, do mundo. A rebeldia e o enfrentamento também eram comumente tematizados, especialmente o tema "contrário", e diversas pessoas poderiam ser homenageadas ou ridicularizadas, de prostitutas e donas de casa a políticos e comerciantes. Elas seriam "uma versalhada alusiva aos principais acontecimentos políticos e sociais ocorridos no ano" (TOBLER, 1949), seriam "modernizadas", pois "adaptam-se ao momento. São um mixto de ironia e malícia disfarçadas" (LEMOS, 1940). De fato, a crítica social e política parecia ser um elemento constituinte dessas organizações. Não estranha que, por ocasião dos concursos de bois, que aparecem nos anos 1930 e teriam um importante papel no disciplinamento e controle dessas

\footnotetext{
${ }^{4}$ Em 1947, por exemplo, Zé Igarapé cantava "te arreda da frente, deixa meu povo passar, que esse ano eu te faço, tu me arrespeitar", e o cantador Eloi que ia reunir, guarnecer, e pedia silêncio "pro contrário ver" (OGB, 25/6/1947). A "luta (dinâmica) dos contrários" dava sentido às relações entre os bumbas. Nestes, o contrário é aquele que é contra, que é inimigo, que é adversário (PRADO, 1977). Com o processo de apropriação cultural, do que se poderia denominar de desbarbarização dos bumbas, quando eles paulatinamente se afastam da violência física.
} 
organizações festivas, fossem descontados pontos daqueles que cantassem toadas consideradas "políticas".

Além disso, durante as festas, os modos de vestir revelavam diferenças sociais e culturais entre aqueles que participavam dos bumbas. Se, em alguns grupos, predominariam papel e plástico, em outros dominariam as lantejoulas e miçangas, os veludos e sedas (TRB, 23/6/1933, p. 6; MAIOBA, 1937; OGB, 5/7/1948). Alguns brincantes usavam chapéus de palha simples, outros chapéus enfeitados com fitas, espelhos e diversos detalhes. Além de terem formas diferentes de brincar, seus personagens pareciam ser variados, a exemplo dos "caboclos guerreiros" ou "índios", que se trajavam "de flechas e pomposos penachos" (PCT, 24/6/1905, p. $1 ; 19 / 6 / 1924$, p. 1), “cobrem-se de lantejoulas e desaparecem sob um montão de pennas, pulando ao som dos maracás e pandeiros" (PCT, 29/6/1910, p. 1); ou ainda o casal negro Pai Francisco e Mãe Catirina: ele, caracterizado especialmente por um chapéu e um facão preso à cintura, seria um personagem vivido por um homem forte e/ou valente; ela, uma personagem essencialmente cômica que costumava usar trajes espalhafatosos, seria a principal responsável pelos risos e gargalhadas da platéia; mas ambos, aos seus modos, poderiam estimular brigas entre os grupos (PCT, 22/6/1900, p. 3; 27/6/1907, p. 2; MACEDO, 1926; TRB, 20/6/1930, p. 5; MENEZES, 1950, p. 1; COSTA, 1953; ALVES, 1955, p. 4).

\section{Os bumbas por escrito: os letrados e seus debates}

Enquanto as fogueiras, os bailes e forrobodós, e as diferentes organizações festivas davam múltiplos ritmos à Ilha, ocorria uma verdadeira batalha entre diversos letrados, em torno dos significados, origens e autenticidade dos bumbas e, mais ainda, sobre o(s) lugar(es) que esses repertórios deveriam ou poderiam ocupar no campo simbólico das tradições, cultura e identidade da região e da nação. Sugiro que estes debates, às vezes velados, mas sempre difundidos, cujas idéias centrais dialogariam intensamente com questões análogas de caráter nacional e internacional, estiveram profundamente imbricados na legitimação de determinadas práticas, notadamente aquelas anteriormente sugeridas, em benefício ou prejuízo efetivo de diferentes sujeitos, setores e grupos sociais.

Embora este tenha sido um movimento descontínuo, sobretudo a partir da década de 1920, diferentes órgãos da imprensa escrita e alguns letrados, contrariamente ao que ocorreu durante o século XIX e praticamente toda a Primeira República, passaram a identificar o bumba-meu-boi como o elemento fundamental do patrimônio cultural regional, que pertenceria e deveria ser preservado por todos os maranhenses, independentemente de suas 
diferenças e desigualdades, enquanto o principal elemento diacrítico da região. ${ }^{5}$ Este movimento se processaria em intensa aproximação com a busca de definição de "cultura brasileira" e da "identidade nacional".

Esta operação esteve comumente acompanhada de um conjunto heterogêneo de narrativas, insistentemente repetidas ao longo dos anos, cujo objetivo era contar e fixar determinadas histórias da origem e significados dos bumbas. Assim, enquanto alguns afirmavam que os bois seriam uma "usança africana" (PCT, 29/6/1910, p. 1; LISBOA, 1947, p. 105; LEMOS, 1940), outros asseveravam se tratar de um gênero artístico ou instituição indígena" (MACEDO, 1926; MELO, 1952), ou ainda "uma tradição portuguesa" (COSTA, 1953). Numa aproximação com histórias ainda mais distantes, alguns veriam nos bumbas uma "reminiscência da festa pagã dos egípcios, imitação à do Boi-Apis" (REIS, 1951, p. 70).

Mas esta série de interpretações das origens do boi que tendia a dar-lhe uma única origem, negro-africana, indígena, portuguesa ou egípcia, parece ter sido fortemente questionada a partir dos anos 1930. Centrado, nos anos 1940-50, na identificação de elementos "africanos" e do "seio do povo", numa perspectiva consoante com as agendas de diversos pesquisadores nacionais, para Vieira Filho, leitor e comentador do cubano Fernando Ortiz e muito próximo da produção antropológica e folclorista de sua época, "a única segurança é que [o boi] nasceu na colônia, ao influxo dos três povos formadores da nacionalidade", o que poderia ser notado pelo seu auto. "Pai Francisco, o negro que mata o boi para tirar-lhe a língua, é escravo de uma fazenda. O amo, o dono do boi de estimação, é português. Os tapuios ou caboclos reais, são índios” (VIEIRA FILHO, 1954, p. 77).

Outro reconhecido "estudioso do folklore maranhense" (DNT, 15/6/1941, p. 5) e inspirado por tendências do movimento modernista era Fulgêncio Pinto, que teria particular atuação nos anos 1930-40. Além de escrever ele também organizava "festas regionalistas" nos "salões nobres" de São Luís com produções cujo referencial estético eram "os costumes do caboclo da Ilha", produzindo "toadas estilizadas do bumba-meu-boi e cantigas populares", a exemplo do que ocorrera em junho de 1941 (DNT, 15/6/1941, p. 5). Pinto também já havia

\footnotetext{
${ }^{5}$ De folguedo insólito e oposto à boa ordem, à civilização e à moral (O IMPARCIAL, 1868), ocasião de violência e "cenas lamentáveis" (PCT, 25/6/1902, p. 1), "incômoda usança" (PCT, 29/6/1916, p. 4), batuque e berreiro perturbador do sossego público que "quase sempre termina em confusão" (PCT, 23/6/1917), o bumbameu-boi passaria a ser identificado como "festa rústica" produzida graças à "índole mansa do povinho do Maranhão" (PCT, 23/6/1922, p. 1), "quadra de satisfação para o caboclo" (DNT, 25/6/1938), "o maior divertimento de nossa classe inculta" (LEMOS, 1940), e, finalmente, seria definido como "tradição da terra maranhense, exemplo único no Brasil" (OGB, 5/7/1948), cujos "propósito" e "espiritualidade" seriam compartilhados por "brancos e pretos, velhos e moços" (OGB, 2/7/1942, p. 4), sendo "assistido por todos, em terreiros, praça pública ou salões aristocráticos" (MELO, 1952), enfim, "coisa essencialmente nossa" (PGB, 4/4/1950, p. 4).
} 
afirmado que o bumba-boi seria constituído por elementos das "três raças" formadoras do "povo" brasileiro, e que este povo e suas festas representariam "forças que hão de gerar uma arte verdadeiramente nacional" (PINTO, 1941, p. 10). De fato, tornar-se-ia comum a idéia de que, na festa do boi, o momento em que se "plasmou a nacionalidade" seria reatualizado, pois especialmente "no popular auto se acham representadas as três raças que se amalgamaram para tornar a nossa nacionalidade, vistas atravéz de um episodio cômico que dá oportunidade para explendidas demonstrações da poesia popular" (CRUZEIRO, 28/6/1947). Do boi, cuja história seria uma "mistura confusa", "exala o perfume virgem do caldeamento étnico da nacionalidade, suas origens vêm do âmago profundo da raça brasileira" (PGB, 4/4/1950, p. 4). Relacionava-se, assim, num momento histórico e num contexto social propícios, o "popular", o "regional" e o "nacional".

Apesar de não se reduzir a tal, certamente, a interpretação da origem dos bumbas como resultado dos contatos entre as "raças" formadoras da nação se vincula ao discurso da "democracia racial" e do Brasil positivamente mestiço. Esta interpretação foi aceita sendo difundida até a contemporaneidade, embora tenha sido freqüentemente questionada. De fato, as narrativas acerca dos significados e origens dos bois são estruturadas no campo denso e tenso em torno do qual gravitam questões sobre "raça", classe e identidade no Brasil.

A busca dos sentidos de uma identidade nacional tem sido o objeto de estudo ou a inquietação de diversos intelectuais desde o século XIX, como Nina Rodrigues, Euclides da Cunha e Silvio Romero que, na Primeira República, pensando o Brasil e discutindo a viabilidade de uma civilização nos trópicos, encontrariam dois obstáculos, a "raça" e o clima, diante do que a solução seria o embranquecimento da população através da vinda de imigrantes europeus (OLIVEN, 2003; SCHWARCZ, 1993). Do modernismo à chamada Era Vargas, particularmente com Mário de Andrade e Gilberto Freyre, a questão da brasilidade positivamente mestiça foi disseminada pelos quatro cantos do país, inclusive no Maranhão, embora até pelo menos final da década de 1940, alguns importantes intelectuais e políticos, como Achilles Lisboa (1947) insistissem em defender abertamente aquele embranquecimento como solução para os problemas sociais do estado. Na contemporaneidade, apesar de muitos autores se posicionarem diversamente do ponto de vista teórico e metodológico, como DaMatta (1981) e Ortiz (1984), a busca de uma definição de "cultura brasileira" e da identidade nacional continua sendo uma questão tida como fundamental.

Esta discussão parece ter sido maximizada com a atual intensificação do debate sobre questões raciais, no qual, de maneira geral, alguns pesquisadores, como Maggie (2005), defendem "o ideário modernista", rememorando-se que Macunaíma é o "herói de nossa 
gente" e não o "herói de nossa raça", um mito que imaginaria um Brasil misturado e não uma nação multi-étnica, mito que, como parece sugerir Fry (2000), seria um mapa para a ação social e o compromisso com o igualitarismo; e outros, que, como Guimarães (2002; 2003), criticam exatamente aquele ideário e a idéia freyreana de "democracia racial", que obliteraria e escamotearia as desigualdades sociais baseadas em critérios de "raça"/cor.

Não estranha que hoje, no Maranhão, a discussão acerca dos significados e das origens dos bois tenha voltado à tona de maneira intensa. Neste contexto, alguns perseguiriam a idéia de uma certa "maranhensidade" que, como sua co-irmã, a "baianidade", ou sua irmã nacional, a "brasilidade", ou ainda suas parentas internacionais, a exemplo da "galicidade" (DARNTON, 1986), seria, antes de tudo, um lugar para se vivenciar valores coletivamente partilhados. Aqui, os diferentes bois estariam todos eles imbricados na "identidade maranhense". De outro lado, setores ligados, por exemplo, ao Movimento Negro, criticariam tal perspectiva elegendo os bois de zabumba (marcados pela forte presença de negros) como um repertório que seria o símbolo exemplar da "identidade afro-maranhense" (ver, por exemplo, SILVA, 2008). Diferentes setores de esquerda escolheriam, por sua vez, os bois de matraca (caracterizados pelo uso desse instrumento de madeira, que pode variar de alguns centímetros a mais de um metro; no passado estes bois eram aqueles comumente vistos como os mais violentos) como agrupamentos que estariam efetivamente ligados aos mais pobres e à sociedade local. Restariam então os bois de orquestra (que usam instrumentos de sopro, bois ditos modernizados e de forte presença das classes médias, compostas em sua maioria por brancos e mestiços claros) para o lugar das festas de todos, particularmente dos turistas.

Ora, além de se reconhecer que os usos e abusos dos bois diante dos discursos referentes a questões raciais e identitárias constituem uma prática recorrente, e estiveram freqüentemente relacionados às terras do Maranhão no solo brasileiro, necessitando serem pensados desde estes lugares, talvez seja relevante considerar que, muitas vezes, em nome da maranhensidade festiva, algumas histórias são esquecidas, como, por exemplo, as tentativas de disciplinamento dos cordões de bois; os diversos indeferimentos dos pedidos feitos à polícia para que essas brincadeiras pudessem sair durante os festejos juninos; as tentativas, muitas das quais sem sucesso, de afastá-los do centro de São Luís, afinal, esta cidade e o estado seriam a terra de uma gente culta, elegante e refinada; a construção de um padrão ideológico, paradigmaticamente observável em José Sarney Costa (1953), segundo o qual a "civilização" dos bumbas implicaria irremediavelmente sua descaracterização; o uso

\footnotetext{
${ }^{6}$ Para uma crítica a este "discurso ideológico”, ver PINHO (1998).
} 
particular de metáforas racistas para falar sobre diferentes repertórios culturais da região, quando, comumente, os bumbas foram vistos como "usança africana que nos veio com a escravidão do negro e continua, aqui mesmo dentro de nossa Capital, a dar-nos o triste espetáculo de uma civilização bastarda" (LISBOA, 1947), enquanto que outros símbolos da região, notadamente aqueles de marca européia como a Atenas Brasileira ${ }^{7}$ e a São Luís francesa $^{8}$, seriam "a brancura lirial de nossas tradições gloriosas” (BRITO, 1957).

De fato, a representação maranhense-ateniense, embora seja um pretenso marcador identitário regional, é tornada possível no contexto da ideologia do branqueamento, que é de caráter nacional e mesmo latino-americano (STEPAN, 1991). Ela pode ser interpretada como um regionalismo que foi gestado e estruturado como uma refinada idéia-imagem local daquela ideologia. A partir dos anos 1930, a Atenas Brasileira e a ideologia do branqueamento deixam de ser padrões centrais de referência para a efetivação de práticas e construção de representações, respectivamente, do Maranhão e do Brasil. As idéias de civilização e cultura europeiamente entendidas foram levadas muito a sério pelas elites letradas do Maranhão. Um olhar atento permite notar, por exemplo, que mesmo nas ocasiões de discursos ufanistas em defesa das "tradições populares", anunciadas como pertencentes a todos, costumava-se reconhecer que esses eram "divertimentos a que se entregam justamente as classes menos favorecidas da sorte", e que por reunirem "grandes massas do povo exigem os cuidados e a proteção das autoridades" (PGB, 21/6/1950, p. 4); alguns intelectuais, particularmente aqueles desvinculados do mundo das pesquisas folclóricas, insistiam em ver os bumbas como "folguedo bárbaro" (LISBOA, 1947), nada mais que "uma mistura de animalidade com perversão" (BURNETT, 1954, p. 2). Enfim, sugeriria ser necessário considerar também estas ocasiões em que os bumbas-meu-boi foram apresentados mais como inimigos do que como aliados do São João e da cultura e sociedade regional, cujas elites letradas quase sempre pretendiam que fosse um exemplo para o Brasil.

As elites letradas maranhenses tentaram, a todo custo, europeizar e, sob certo aspecto, embranquecer o patrimônio cultural e identitário regional. E tal operação, muitas vezes, foi acompanhada por um outro empreendimento, a tentativa de ignorar ou execrar os elementos que eram identificados como herança de indígenas e africanos. Elas aceitavam que havia altas culturas, e que estas se localizavam na Europa. Crentes de que a civilização se desenvolveu

\footnotetext{
${ }^{7} \mathrm{Na}$ tentativa de construção da identidade nacional sob o patrocínio do Estado Imperial, no início do século XIX, uma série de intelectuais e poetas maranhenses (cujo principal expoente é Gonçalves Dias) começou a se destacar no plano nacional. Por causa dessa cultura inclinada às letras, a região recebeu (ou se deu) o aposto de "Atenas Brasileira", símbolo este frequentemente reatualizado. Ver, dentre outros, ALBERNAZ (2003), BARROS (2005; 2006), BORRALHO (2008), CORRÊA (1993), MARTINS (2002).

${ }^{8}$ Sobre a reverenciada e questionada fundação de São Luís pelos franceses, ver LACROIX (2000).
} 
plenamente em regiões recordadas em um passado distante, como a Grécia, acreditavam poder compartilhar de um pedaço, ainda que ínfimo, dessa civilização e dessa cultura. Fazendo-o, tinham certeza de que estavam contribuindo para o progresso do Brasil e da América. Nessa perspectiva, a representação Atenas Brasileira pode ser entendida como uma rebuscada tentativa de europeização e embranquecimento cultural e identitário do Maranhão e do maranhense. A idéia de Atenas Brasileira não é essencialmente racista, mas o racismo parece ser uma de suas principais marcas. Obviamente, a intensa difusão dos bumbas (e de outros repertórios culturais identificados com África e com os povos nativos, a exemplo do tambor de mina, do tambor-de-crioula e da pajelança) contribuiu para minar a construção de uma identidade regional fundada em padrões branco-europeus. Se não foram ações revolucionárias, as estratégias e práticas de resistência cotidiana ${ }^{9}$ dos sujeitos produtores dessas organizações festivas não deixaram de promover transformações, como a inflexão da imagem da região, que passou a ser pensada desde o universo festivo dos bumbas e da dita cultura popular e negra.

Chegando a este ponto, uma suspeição mereceria ser colocada. Ora, parece haver uma relação entre a representação dessas práticas festivas como tradicionais e arcaicas (para o bem ou para o mal, este seria seu legítimo lugar no mundo), a proibição de que elas, nos seus dias mais intensos, fossem ao (civilizado) centro da cidade, a forte desigualdade social e racial que marcava a região, e a negação aos brincantes e festeiros de que suas práticas fossem lugar de crítica política e reivindicação de cidadania. De fato, é possível que, ao engendrar-se um conjunto de idéias e representações sobre os bumbas que os relacionavam diretamente ao passado, ao imutável e necessário mundo da tradição (lido como algo antagônico à “civilização" e ao "progresso"), construía-se também um repertório ideológico que justificaria o afastamento dos agentes sociais relacionados aos bumbas das (perspectivas de) mudanças e transformações sociais do presente (e do futuro), particularmente aquelas referentes à conquista de direito e cidadania. Neste caso, não permitir que os bumbas fossem à cidade durante os dias fortes dos festejos juninos foi algo tão real quanto a exclusão social de grande parte daqueles que freqüentemente se encarregavam de produzir essas brincadeiras. Assim, a ocupação coletiva do centro de São Luís pelos grupos de boi (exatamente durante os dias

\footnotetext{
${ }^{9}$ Quatro critérios têm sido exigidos para a "verdadeira" resistência: tem de ser coletiva e organizada, e não privada e desorganizada; deve ser fundamentada e altruísta, em vez de oportunista e egoísta; deve ter conseqüências revolucionárias; deve negar ao invés de aceitar a base da dominação. Mas essa é uma noção de resistência que deve ser questionada, pois há "formas cotidianas de resistência", isto é, práticas privadas e isoladas de resistência, uma espécie de resistência velada que nunca se arrisca a contestar as definições formais de hierarquia e poder. Para a maioria das classes subordinadas que tiveram poucas perspectivas de melhorar seu status, essa forma de resistência tem sido a única opção. Ver SCOTT (1976; 1985).
} 
fortes daquela que era, reconhecidamente, a mais importante festa do estado) pode ser interpretada como um grito de existência, uma manifestação de alteridade e uma ocasião de reivindicação de cidadania. Aqui, estaria a "cultura" em mobilização na dinâmica e na mudança social?

Na primeira metade do século XX, a definição dos bumbas nas linhas da ideologização da mestiçagem brasileira e da brasilidade harmônico-festiva, esteve, direta ou indiretamente, aliada a uma tentativa de "pacificação" dos bumbas-meu-boi e de ocultamento de diferenças e desigualdades. Nesse contexto, consolidar-se-ia a interpretação dessas organizações festivas como "cultura popular", sendo também folclorizadas, deixando de ser vistas como "bárbaro e incômodo brinquedo", o que consistiu em um processo descontínuo e marcado por heterogeneidades. Este movimento pode ser observado de maneira exemplar no ocultamento da capoeira ou das práticas de luta e enfrentamento corporal, e na valorização da trova pela imprensa, pelos folcloristas e por alguns membros do povo-de-boi, particularmente a partir dos anos 1940. Muitos dos que se tornam donos ou amos de bois a partir desse período, como Alaurino Campos de Almeida (1997, p. 76 ), mostram que tentar evitar a violência ao nível dos discursos e da prática, torna-se algo fundamental para ser aceito no novo cenário que se abre, aquele da cultura negra no poder instituído (SANTOS, 2005), da cultura popular tornando-se foco de diversos órgãos e instituições estatais (ALBERNAZ, 2004, BRAGA, 2000).

É evidente que múltiplas formas de ver e de produzir os bumbas no contexto dos festejos juninos no Maranhão da primeira metade do século XX estão relacionadas, de diferentes maneiras, às questões levantadas por essas discussões e às práticas, representações e instituições que têm sido recorrentemente destacadas em diferentes abordagens que analisam as relações entre cultura e identidade nacional, dentre as quais, podem-se destacar: uma íntima relação entre a investigação acerca dos costumes populares e a criação de uma dada nacionalidade ou manifestação do caráter nacional, algo que pode ser observado na Europa pelo menos desde o período moderno (DAVIS, 1990), a partir de quando passam a ser constantes as associações entre estética, povo, "raça", folclore, cultura e identidade nacional a "descoberta do povo" (BURKE, 1989), a emergência da "rusticofilia" (CERTEAU, 1995), o que influenciaria profundamente os movimentos modernista (MORAES, 1978; 1988), regionalista (ALBUQUERQUE JUNIOR, 1994) e folclorista, que tem uma forte mobilização nacional sobretudo a partir da década de 1940 (VILHENA, 1997).

Também se deve considerar as discussões levantadas pelos congressos afro-brasileiros, realizados em Recife (1934) e Salvador (1937), em torno do "problema do negro" no território 
nacional, e a institucionalização acadêmica das discussões sobre as relações entre negros e brancos no Brasil, a partir dos anos 1930 (SANSONE, 2002); o Estado Novo, que institui uma política paternalista e repressiva em relação à cultura dita popular (MATOS, 1982; OLIVEN, 1984), de "louvação" à "raça negra", modelo de trabalhadores (GOMES, 1988, 1996), mas também período de forte disciplinamento e perseguição a elementos das manifestações culturais produzidas particularmente por pobres e negros; e a institucionalização da ação do Estado brasileiro no campo da cultura (FALCÃO, 1984), quando, entre 1937 e 1966, a preservação dos bens de valor cultural visava desenvolver atividades como estudar, documentar, consolidar e divulgar os bens culturais isolados, promovendo um mapeamento cujo objetivo era não deixar que esses bens desaparecessem em ruínas (TELLES, 1977).

Assim, reconhece-se que, além da associação entre certos repertórios culturais, notadamente aqueles identificados como "culturas do povo", e algumas identidades nacionais, houve também uma associação entre manifestações culturais e algumas identidades regionais, como se pode observar, por exemplo, nos casos do Maranhão, Rio de Janeiro (AUGRAS, 1998; BASTOS, 1996; CUNHA, 2001; MATOS, 1984, SOHIET, 1998), Bahia (LÜHNING, 1995; SANTOS, 2005), Pernambuco (GUILLEN, 2005) e Amazonas (FIGUEIREDO, 1996). E se a "Nação", quando associada ao "povo", acaba obliterando um conjunto múltiplo e vasto de sujeitos e experiências sociais, uma vez que passou a ocupar o lugar de sujeito da história, (CHALHOUB, 1997) o mesmo se pode dizer da "Região". Ambas são freqüentemente pensadas como campos de homogeneidade e univocidade, sendo a festa a ocasião máxima para a atualização do ethos coletivo. De fato, questões acerca de "identidade maranhense" precisam ser posicionadas tanto horizontal (região-região) quanto verticalmente (regiãonação) no contexto das relações entre cultura e identidade no Brasil.

\section{Considerações finais}

Como já bem lembrara Chartier em sua conhecida crítica a "Histórias que os camponeses contam: os significados de Mamãe Ganso”, de Darnton (1986), é questionável a idéia de que se poderia localizar um ethos nacional ou distinguir-se uma duradoura e específica identidade nacional (CHARTIER, 1996). Ao contrário, reconhece-se que é problemático relacionar a cultura à história nacional - e também regional -, que há desigualdades na apropriação de materiais ou práticas comuns (CHARTIER, 1996, p. 14-15), e que o essencialismo ignora a multiplicidade de vozes contemporâneas em luta, em negociação, e em jogo no interior de uma cultura (FERNANDEZ, 1988, p. 118). Nesta 
perspectiva, faz-se mister escapar de uma compreensão de "festa, "cultura" e "tradição" como variáveis capazes de apresentar uma certa totalidade, continuidade e permanência, para entendê-las como espaços nos quais se podem pensar diferenças, desigualdades e mudanças, afinal, a multiplicidade não pode ser ignorada por uma idéia de cultura como símbolos $\operatorname{compartilhados}^{10}$ (THOMPSON, 1998; CHARTIER, 1996; FERNANDEZ, 1988).

Os bumbas-meu-boi, enquanto repertório cultural e festivo, constituíam elementos polifônicos, reveladores de recriações, diferenças e desigualdades. Havia tensões entre sujeitos que nem sempre estavam reconciliados nas festas que tinham os bois como corolário. Nessas festas, para além da mistura e do encontro, longe de se suspender conflitos e se revitalizar comunidades imaginadas nacionais e regionais, as hierarquias sociais eram ritualizadas e teatralizadas. O "povo-de-boi", como às vezes eram chamados os que se envolviam com os bumbas, e os diferentes sujeitos que participavam dos festejos, se construíam harmonias, com freqüência afirmavam diferenças em embates que se davam no cotidiano e por ocasião das festas.

\footnotetext{
${ }^{10}$ Para esta idéia de cultura, ver GEERTZ (1989).
} 


\section{Referências}

\section{Fontes}

Periódicos

DIÁRIO DO MARANHÃO. Jornal do Comércio, Lavoura e Indústria. São Luís, 1870-1920.

DIÁRIO DO NORTE. São Luís, 1937-45.

JORNAL DO DIA. Um Órgão a Serviço da Verdade. São Luís, 1953-60.

O GLOBO. Jornal da Manhã. São Luís, 1939-49.

O IMPARCIAL. São Luís, 1861-98.

O IMPARCIAL. Matutino Independente. São Luís, 1926-62.

PACOTILHA. Hebdomadário crítico e noticioso. São Luís, 1880-1938.

PACOTILHA - O GLOBO. São Luís, 1949-58.

REVISTA ATHENAS. São Luís, 1939-42.

REVISTA DA ACADEMIA MARANHENSE DE LETRAS. São Luís, 1914-56.

REVISTA DO INSTITUTO HISTÓRICO E GEOGRÁFICO DO MARANHÃO. São Luís, 1930-56.

TRIBUNA. Matutino Independente. São Luís, 1930-7.

Literatos, memorialistas, folcloristas e outros

ANDRADE, M. de. Macunaíma. Belo Horizonte/Brasília: INL; Fundação Pró-Memória, 1984 (1928).

ALVES, I. R.. Noite de São João. Jornal do Dia, São Luís, 25 de jun. de 1955.

BURNETT, J. C. L. São João desconhecido. Jornal do Dia, São Luís, 24 de jun. de 1954. Boi Morto. Jornal do Dia. São Luís, 30 de jun. de 1954.

COSTA, J. S. Notas sobre o Bumba-meu-boi. O Imparcial. São Luís, 26 de jul. de 1953.

COSTA, Ribamar. Noite do Balão e da Saudade. Tribuna, São Luís, 24 de jun.de 1934.

DONCRI. Linda Noite de São João. Diário do Norte, São Luís, 2 de jul de 1939.

FREYRE, G. Casa-grande \& senzala. Rio de Janeiro: Record, 1995 (1933). 
LEMOS, B. Festas tradicionaes de nossa terra. Diário do Norte, São Luis, 23 de jun. de 1940.

LISBOA, A. A imigração e a lepra. Revista de Geografia e História do Maranhão, São Luís, 1947.

LOPES, A. Folclore Maranhense. Diário do Norte, São Luís, 20 de jun. de 1942.

MACEDO, E. de. Noite de São João. Pacotilha, São Luís, 23 de jun. de 1926.

MAGALHÃES, C. de. A poesia popular brasileira. Rio de Janeiro: Biblioteca Nacional, 1973.

MAIOBA, J. Bumba-meu-boi. Diário do Norte, São Luis, 26 de jun. de 1937.

MEIRELES, J. de. Sentidos versos meus... Novidades, São Luís, 07 de set. de 1950.

MELO, A. Bumba-meu-boi. Novidades, São Luís, 10 de mar. de 1952.

OLIVEIRA, A. de. Retalhos Dominacaes. Diário do Norte, São Luís, 2 de jul. de 1939.

OLIVEIRA, F. de. Noite de São João. Diário do Norte, São Luis, 24 de jun. de 1939.

PEDRO, J. Festa de São João. Diário do Norte, São Luís, 25 de jun. de 1941.

PEREIRA, R. São João de hontem e São João de hoje. Folha do Povo, São Luís, 22 de jun. de 1929.

PINTO, F. Festa de S. João. Revista Athenas, São Luís, jun. de 1941.

TOBLER, J. Tradição e crença de um povo. Correio de Timon, Timon, 19 de jun. de 1949.

VIANA, L. Os fogos de São João. Pacotilha, São Luís, 25 de jun. de 1910.

VIEIRA FILHO, D. O negro na poesia popular. Revista do Maranhão, São Luís, mar. de 1951.

A linguagem popular do Maranhão. Revista de Geografia e História do Maranhão, São Luís, n. 4, p. 67-108, dez. de 1953. 1954.

Folklore sempre. Revista de Geografia e História do Maranhão, São Luís, dez. de

Outros documentos impressos

MARANHÃO. Diário Oficial do Estado do Maranhão. Polícia Civil. Portaria n. 56, de 23 de junho de 1946.

Portaria n. 49, de 17 de junho de 1947. 
Portaria n. 28, de 19 de jun. de 1948.

Portaria n. 21, de 8 de jun. de 1949.

Portaria n. 46, de 30 de maio de 1952.

Depoimentos

ALMEIDA, A C. Depoimento. In.: MARANHÃO. Memória de Velhos. São Luís: LITHOGRAF, 1997. V. 3.

MARANHÃO. Memória de Velhos. São Luís: LITHOGRAF, 1997. V. 3.

PASSOS, M. V. Depoimento. In.: MARANHÃO. Memória de Velhos. São Luís: LITHOGRAF, 1997. V. 3.

SANTOS, C. Depoimento. In.: MARANHÃO. Memória de Velhos. São Luís: LITHOGRAF, 1997. V. 3.

\section{Bibliografia}

ABREU, M. O império do Divino. Rio de Janeiro: Nova Fronteira; São Paulo: FAPESP, 1999.

ALBERNAZ, L. S. F. O "urrou” do boi em Atenas. 2004. Tese (Doutorado em Ciências Sociais) - Instituto de Filosofia e Ciências Humanas, Campinas, Universidade Estadual de Campinas, 2004.

ALBUQUERQUE JÚNIOR, D. M. O Engenho Anti-Moderno. 1994. 501 f. Tese (Doutorado em História Social) - IFCH, Campinas, Universidade Estadual de Campinas, 1994.

ALMEIDA, J. de. Todas as festas, a festa? In.: SWAIN, T. (Org.). História no Plural. Brasília: Editora da UNB, 1994.

ASSUNÇÃO, M. R.. Cultura popular e sociedade regional no Maranhão do século XIX. Revista de Políticas Públicas. São Luís: EDUFMA, p. 29-67, 1999.

AUGRAS, M. O Brasil do Samba-Enredo. Rio de Janeiro: Ed. FGV, 1998.

BAKHTIN, M. M. A cultura popular na Idade Média e no Renascimento. São Paulo: HUCITEC; Brasília: Editora UNB, 1987.

BARROS, A. E. A. O Pantheon Encantado: culturas e heranças étnicas na formação de identidade maranhense. 2007. 317 f. Dissertação (Mestrado em Estudos Étnicos e Africanos) - IFCH, Programa Multidisciplinar de Pós-Graduação em Estudos Étnicos e Africanos, CEAO, Salvador, UFBA, 2007. 

$120,2005$.

A terra dos grandes bumbas. Caderno Pós Ciências Sociais, São Luís, v. 2, p. 94Culturas popular e erudita nas linhas de maranhensidade. Boletim da Comissão Maranhense de Folclore, São Luís, n. 35, p. 9-12, ago. de 2006.

BASTOS, R. J. de M.. A "Origem do Samba” como Invenção do Brasil (Por que as Canções Têm Música?). Revista Brasileira de Ciências Sociais, São Paulo, n. 31, ano 11, 1996.

BORRALHO, J. H. de P. A Athenas Equinocial: a fundação de um Maranhão no Império Brasileiro. 2009. Tese (Doutorado em História) - Niterói, UFF, 2009.

BRAGA, A. S. R. Folclore e política cultural. A trajetória de Domingos Vieira Filho e a Institucionalização da Cultura. 2000. 163 f. Dissertação (Mestrado em Políticas Públicas) Centro de Ciências Sociais, São Luís, Universidade Federal do Maranhão, São Luís, 2000.

BURKE, P. Cultura Popular na Idade Moderna - Europa, 1500-1800. São Paulo: Cia. das Letras, 1989.

BUZAR, B. O Vitorinismo: lutas políticas no Maranhão. São Luís: Lithograf, 1998.

CARVALHO, M. M. P. de. Matracas que desafiam o tempo. São Luís: [s. e.], 1995.

CANJÃO, I. M. F.. Bumba-meu-boi, o rito pede “passagem” em São Luís do Maranhão. Dissertação (Mestrado em Antropologia Social) - Universidade Federal do Rio Grande do Sul, Porto Alegre, 2001.

CERTEAU, M. de. A beleza do Morto. In.: . A Cultura no Plural. 2. ed. Campinas: Papirus, 1995.

CHALHOUB, S. (coord.). Cultura e Diversidade no Brasil: para além da história da identidade nacional (séculos XIX e XX) (Projeto de Pesquisa). 1997. Disponível em http://www.unicamp.br/cecult. Acesso em 10 de jul. de 2007.

. Cidade Febril. São Paulo: Cia. das Letras, 1996.

Visões da liberdade. São Paulo: Cia. das Letras, 1990.

Trabalho, Lar e Botequim. São Paulo: Brasiliense, 1986.

CHARTIER, R. Textos, símbolos e o espírito francês. História: questões e debates, Curitiba/PR, n. 24, jan.-jul. de 1996.

CORRÊA, H. M. M.. Bumba meu boi do Maranhão: a construção de uma identidade. 2002. Dissertação (Mestrado em História do Brasil) - IFCH, Universidade Federal de Pernambuco, 2002.

CUNHA, M. C. P. Ecos da Folia. São Paulo: Cia. das Letras, 2001.

2002.

(org.). Carnavais e outras f(r)estas. São Paulo: Editora da UNICAMP, CECULT, Apresentação. In.: . (Org.) Carnavais e outras f(r)estas. São Paulo: Editora 
da UNICAMP, CECULT, 2002.

DAMATTA, R. A mensagem das festas: reflexões em torno do sistema ritual e da identidade nacional. Sexta-Feira - Antropologia, Artes e Humanidades, n. 2, ano 2, Festas. São Paulo, Pletora, abr. de 1998.

Carnavais, malandros e heróis. Rio de Janeiro: Zahar, 1981.

DARNTON, R.. Histórias que os camponeses contam: os significados de Mamãe Ganso. In: O Grande Massacre de Gatos e outros episódios da história cultural francesa. Rio de Janeiro: Graal, 1986.

DAVIS, N. Z. Culturas do povo. São Paulo: Paz e Terra, 1990.

DUVIGnAUd, J. Festas e Civilizações. Ceará: Edições UFC / Rio de Janeiro: Tempo Brasileiro, 1983.

FALCÃO, J. A. A política cultural e democracia: a preservação do patrimônio histórico e artístico nacional. In.: MICELI, S. (org.). Estado e cultura no Brasil. São Paulo: Difel, 1984.

FERNANDEZ, J. Historians Tell Tales: of Cartesians Cats and Gallic Cockfights. The Journal of Modern History, v. 20, n. 1, mar. de 1988.

FERRETTI, S. F. Repensando o Sincretismo. São Paulo: Editora da USP; São Luís: FAPEMA, 1995.

FIGUEIREDO, A. M. A cidade dos encantados: pajelanças, feitiçarias e religiões afrobrasileiras na Amazônia. A constituição de um campo de estudo, 1870-1950. Dissertação (Mestrado em História Social) - IFCH, Campinas, Universidade Estadual de Campinas, 1996.

FRY, P. Politics, nationality and the meanings of "race" in Brazil. Daedalus, 129, 2000.

GEERTZ, C. A Interpretação das Culturas. Rio de Janeiro: LTC, 1989.

GOMES, A. de C. A Invenção do Trabalhismo. Rio de Janeiro: IUPERJ, 1988; 1996.

História e historiadores: política cultural no Estado Novo. Rio de Janeiro: FGV,

GOMES, T. de M.. Um espelho no palco: Identidades sociais e massificação da cultura no teatro de revista dos anos 1920. Campinas, SP: Editora da Universidade Estadual de Campinas, 2004.

Negros Contando (e Fazendo) sua História: Alguns Significados da Trajetória da Companhia Negra de Revistas (1926). Estudos Afro-Asiáticos. Rio de Janeiro, v. 23, n. 1, jan./jun. 2001.

GUILLEN, I. C. M. Xangôs e maracatus: uma relação historicamente construída. Ciências Humanas em Revista, São Luís, EDUFMA, v. 3, n. 2. p. 59-72, 2005.

GUIMARÃES, A. S. A. Como trabalhar com "raça" em sociologia. Educação e Pesquisa, São Paulo, v. 29, 2003. 
Classes, raças e democracia. São Paulo: Editora 34, 2002.

GINZBURG, C. O Queijo e os Vermes. São Paulo: Cia. das Letras, 1987.

LACROIX, M. L. L. A fundação francesa de São Luís e seus mitos. São Luís: EDUFMA, 2000 .

LÜHNING, A. "Acabe com este santo, Pedrito vem aí...”. Mito e realidade da perseguição policial ao candomblé baiano entre 1920 e 1942. Revista USP, São Paulo, dez.-fev., 19951996.

MAGGIE, Y. Mário de Andrade ainda vive? O ideário modernista em questão. Revista Brasileira de Ciências Sociais, São Paulo, v. 20, n. 58. 2005.

MARQUES, F. E. de S. Mídia e experiência estética na cultura popular. São Luís: IU, 1999.

MATOS, C. Acertei no milhar. Rio de Janeiro: Paz e Terra, 1982.

MORAES, E. J. de. A Brasilidade Modernista: sua Dimensão Filosófica. Rio de Janeiro: Graal, 1978.

Modernismo Revisitado. Estudos Históricos. Rio de Janeiro, v. 1, p. 220-238, 1988.

OLIVEN, R. Tradição e modernidade na identidade brasileira. In.: SCOTT, P.; ZARUR, G. Identidade, fragmentação e diversidade na América Latina. Recife: Ed. Universitária da UFPE, 2003.

A relação Estado e cultura no Brasil: cortes ou continuidade? In.: MICELI, S. (org.). Estado e cultura no Brasil. São Paulo: Difel, 1984.

ORTIZ, R. Cultura e identidade nacional. São Paulo: Brasiliense, 1984.

PARÈS, L. N. The Phenomenology of spirit possession in the Tambor de mina. 1997. Tese (Doutorado) - SOAS, University of London, 1997.

PINHO, O. S. de A.. “A BAHIA NO FUNDAMENTAL”: Notas para uma Interpretação do Discurso Ideológico da Baianidade. Revista Brasileira de Ciências Sociais, São Paulo, v. 13, n. 36, fev. 1998.

PRADO, Regina Paula dos. S. Todo Ano Tem: as festas na estrutura social camponesa. 1977, 244 f. Dissertação (Mestrado em Antropologia Social) - PPGAS. Rio de Janeiro: Museu Nacional; Universidade Federal do Rio de Janeiro, 1977.

REIS , J. J. Tambores e temores: a festa negra na Bahia na primeira metade do século XIX. In.: (org.). CUNHA, M. C. P. (Org.) Carnavais e outras f(r)estas. São Paulo: Editora da UNICAMP, CECULT, 2002.

REIS, J. R. S. dos. Bumba-meu boi. 3. ed. São Luís: LITOGRAF, 2000.

SANSONE, L. Um Campo Saturado de Tensões. Estudos Afro-Asiáticos, Rio de Janeiro, v. $24,2002$. 
SANTOS, J. T. dos. O poder da cultura e a cultura no poder. Salvador: EDUFBA, 2005.

Divertimentos estrondosos: batuques e sambas no século XIX. In.: SANSONE, L.; et. al. (orgs.). Ritmos em Trânsitos. São Paulo: Dynamus; Salvador: A Cor da Bahia, p. 15-38, 1997.

SCHWARCZ, L. M. O espetáculo das raças. São Paulo: Cia. das Letras, 1993.

SCOTT, J. C. Weapons of the weak: everyday forms of peasant resistance. London: New Haven and London, Yale University Press, 1985.

The Moral Economy of the Peasant. Rebellion and subsistence in Southeast Asia. London: New Haven and London, Yale University Press, 1976.

SILVA, Carlos Benedito Rodrigues da. Tramas da desigualdade: política da cultura e o boi de zabumba do Maranhão. Trabalho apresentado na mesa redonda "Bumba-meu-boi: culturas e identidades, diferenças e desigualdades", III Encontro Regional da ANPUH-MA, São Luís, UFMA, 2008.

SKIDMORE, T. E. Preto no Branco. Rio de Janeiro: Paz e Terra, 1976.

SOARES, Carlos Eugenio Libano. Festa e Violência: os capoeiras e festas populares na Corte do Rio de Janeiro (1809-90). In.: CUNHA, M. C. P. (Org.) Carnavais e outras f(r)estas. São Paulo: Editora da UNICAMP, CECULT, 2002.

SOIHET, R. A subversão pelo riso. Rio de Janeiro: Editora Fundação G. Vargas, 1998.

STEPAN, N. The Hours of Eugenics. London: Cornell University Press, 1991.

TELLES, A. S. Proteção do patrimônio histórico e artístico, monumental, móvel e paisagístico. Cultura, Brasília, n. 27, out./dez. de 1977.

THOMPSON, E. P. Folclore, antropologia e História social. In.: NEGRO, A. L.; SILVA, S (orgs.). As peculiaridades dos ingleses e outros artigos. Campinas: UNICAMP, 2001.

. Costumes em Comum. São Paulo: Cia. das Letras, 1998.

1981.. O termo ausente: experiência. In ___. A miséria da teoria Rio de Janeiro: Zahar,

VIANNA, H. O Mistério do Samba. Rio de Janeiro: Zahar/Ed. UFRJ, 1995.

VILHENA, L. R.. Projeto e Missão. Rio de Janeiro: FGV/FUNARTE/MEC, 1997.

VOVELLE, Michel. Ideologia e mentalidades. São Paulo: Brasiliense, 1991. 